\title{
Internationalization and Leadership
}

\author{
Frank F. Cotae
}

\begin{abstract}
The continuous pursuit of growth and diversification has pressured companies to pursue internationalization for their operations. Understanding the rationales and limitations of such efforts has been the subject of much research for several decades. While researchers have yet to arrive at conclusive directives, many regard internationalization efforts as taking the form of a 3-stage sigmoid. Leadership is seen as the primary factor capable of modifying the 3-stage internationalization sigmoid, since it is responsible for allocating further resources or postponing further expansion. Extant research provides that there is a clear differentiation between management and leadership. This paper presents internationalization and leadership as related concepts that intersect so as to provide a framework for solutions with regards to leadership styles seen to best address organizational decisions with regards to internationalization efforts needed for the third stage of the sigmoid. Conclusions and further research direction are also included as the framework is not seen as exhaustive.
\end{abstract}

Index Terms-Internationalization, sigmoid, leadership, multinational.

\section{INTRODUCTION}

The continuous quest of growth and diversifications has pressured companies to pursue internationalization for their operations as an outlet for achieving better financial results, increase competitive position and market share, reduce business risk and diversify operations. Understanding the rationales and limitations of such efforts has been the subject of much research for several decades.

The pursuit of increased international presence has not come without a cost as the process does carry a certain cost element and it weighs on an MNE's core capabilities and resource inventory. Firms unable to cope with the new demands of continuous internationalization are seen to regress in their registered results. To what extent leadership, can prevent this is the subject matter of this paper. The following sections present a literature focus of the internationalization and leadership, while applying them to actual MNE's predicaments to achieve a certain level of authenticity and applicability for the realization of a set of realistic expectations with regards to modifying the sigmoid.

\section{INTERNATIONALIZATION}

Internationalization is defined as the "process by which firms increase their awareness of the influence of

Manuscript received January 22, 2013; revised March 29, 2013.

Frank F. Cotae is with the Mount Royal University, Canada (e-mail: fcotae@mtroyal.ca). international activities on their future, and establish and conduct transactions with other firms from other countries" [1]. Most of the documented rationales for business entities (SME/MNE) choosing to internationalize their operations fall into three categories: reduce risk, increase profitability, and allow for learning from the core capabilities offered by global partners [2]. These in turn are expected to provide value for future business activities. Although most related literature seems to promote internationalization as the appropriate direction underlying a firm's superior performance attainment, [3]-[6] there are voices that doubt any linear relationship between a firms's degree of globalization and its level of performance [7]-[9]. Other voices merely question the process, devoid of leadership interaction, as the absolute guarantee for increased performance [10], [11]. In summary, internationalization and leadership are seen as the key components resulting in increased or positive firm performance. A multi-stage and scurve hypothesis is advanced here as the model for a multinational firm degree of expansion (DOI) and performance $(\mathrm{P})$ relationship [12]-[14]. There are three distinct stages of internationalization in the life of a firm, best exemplified by the General Sigmoid [14]-[16] model set out in Fig. 1: Stage I (early internationalization); Stage II (later internationalization); and Stage III (excessive internationalization). At the first stage a multinational is expected to incur costs as it sets up "shop" in a foreign place [16], [17], yet these costs are expected to be recovered during the second stage as the firm's performance reaches superior results. The third stage has been a matter of debate as firms engaged in global operations eventually reach a point where increasing the degree of internationalization becomes counterproductive [1] and the firm gradually reaches a level of operational saturation. The saturation point is where the core operational capabilities of a firm are no longer adequate for servicing a large number of global customers, vendors, subsidiaries, retail channels, and associates.

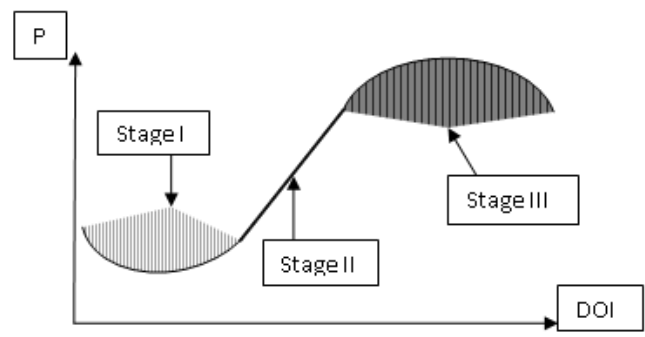

Fig. 1. The general sigmoid 3-stage model.

In addition, during the third stage the cost of maintaining a global operation and/or growing internationally renders the internationalization strategy inefficient and usually requires efforts outside a firm's realm of operational 
logistics/realities. As a result, productivity and profits are expected to decline. Current research has not yet produced a definitive model or factor by virtue of which this stage on internationalization can be predicted or its effects ameliorated, postponed, or diminished. It is therefore necessary for an SME/MNE to continuously attempt to assess and forecast its costs before pursuing higher degrees of internationalization. The task of assessing forecasts, design growth strategies and operational related direction lies with the firm's leadership.

\section{LEADERSHIP}

What is leadership? The concept often gets defined as being related to existing/present management at an organization's different functional and operational levels. "Leadership is the behavior of an individual in directing through communication and interpersonal influence the activities of a group toward a shared goal" [18], [19]. That definition suggests that there is a clear link between management and leadership, though as Kouzes and Posner emphasize, the two roles are quite distinct. As most agree, management is task and process oriented, whereas leadership deals with getting people to do what needs to be done. Managers carry out responsibilities, exercise authority, and worry about how to get things done, whereas leaders are concerned with understanding organizational needs, core capabilities, peoples' beliefs and gaining their commitment [20], [21]. Managers are task-oriented, while leaders are involved with the evolution of task performance. Leadership comes into play as an organization faces the ever evolving need to deal with changes in the business, social, cultural, and political landscapes. It takes leadership to guide a business endeavor under these circumstances. "Leadership is coping with change, whereas management is coping with complexity [22]." The capable leader is "one who can lead others through difficult situations where significant changes are taking place" [12], [22], [23]. Summarizing, while a manager may be successful at operating a global enterprise, the strategic choice related to entering a foreign market or doing business internationally is set by the leadership of an organization; leadership that is expected to have a global mindset with regards to operations [17].

\section{A. Leadership Styles}

Defining leadership as a concept remains amorphic without attaching a clear meaning and path towards effectiveness and choice of leadership styles that are seen to positively affect firm's results. It is of importance to note that all leadership styles are seen to be purposefully oriented towards improving a firm's performance and we only advance that with regards to internationalization and global expansion some leadership styles may be a better match than others. The leadership styles that we have identified are based on extant research and can be summarized as: leadership for sustainability, situational leadership, transformational leadership, [24] and transactional leadership, distributed/shared leadership, relational leadership, ethical leadership, spiritual leadership and authentic leadership. Below we will look at synthesizing each of them as we build a foundation for a model.

Leadership for sustainability is seen to support not only a predilection towards strong corporate social responsibility, but also requiring extraordinary abilities as such individuals are seen to be able to navigate through complex problems and engage groups in dynamic adaptive organizational change [24] A continuous dedication to moral and ethical decisions places this leadership style at the forefront of integrity with regards to decision making processes. The adaptive traits, ability to deal with complex problems and organizational changes does provide for a substantial backdrop for internationalization related decisions.

Situational leadership, according to Goal Path Theory is seen as the result of the intersection of situational modeling and decision making structures [25] or according to Situational Theory as refers to leader-member relations, task structure and position power. The latter, while a valuable theory, it does not support the current path of research and as such we assume the more updated definition of situational leadership [25] as advanced by the Goal and Path Theory. Another framework - The Hersey-Blanchard Situational Leadership Theory - states that instead of using just one style, successful leaders should change their leadership styles based on the maturity of the people they are leading and the details of the task [24], [25]. The last part - details of the task - does carry value in making complex decisions, yet it may be debatable to what extent situational leaders can affect outcomes based on them changing their style based on employee maturity. By this extent IT companies that employ a younger work force may need a less mature leader, and while this may be the case in some IT companies, supporting such a conclusion and claim may seem rushed and without substantiating evidence.

Transformational leadership is seen as leadership that possesses visionary and charisma, it is essentially leadership that motivates followers to transcend their self-interests for a collective purpose, vision, and/or mission [24], [26]. This form of leadership tends to foster trust and admiration toward the leader on the part of followers, and thus they may be inspired to do more than they were originally expected to do. It is seen to assist a company in adopting innovative solutions for solving operational derived issues. Other theorists see transformational leadership as not having any effect upon firms meeting their objectives as these leaders often service firm's short-term goals due to their short-lived tenure as strategists [24], [25]. A short-tenured strategist may not be in the position to take a company toward success or prevent loss during the years of organizational maturity, represented in the sigmoid.

Transactional leadership appears to service short-term economic needs of an organization and is seen as less effective if tasks involve long-term visionary approach to both expansion and future organizational purpose [24], [26]. Internationalization is a long-term plan that involved complex decisions and a set of complex tasks need to be undertaken to assure firm's success; success and timeline that may not be well supported by a series of short-term transactions, even if strategically made.

Distributed and shared leadership involve multiple leaders with distinct but inter-related responsibilities. If the various leaders are unable to agree about what to do and 
how to do it, performance of the team or organization is likely to suffer[27], [28], therefore making this style a bit outside our comfort zone with respect to operating successfully under changing conditions due to the different understanding of the impact of these conditions.

Relational leadership, based on "consistently influencing relationships and collective activities, accomplished by interpreting events and explaining cause-effect relationships [28]"and by influencing people to modify their attitudes, behavior, and goals. Leaders develop and use social networks to gather information and build alliances to increase their influence over decisions [27], [28]. It is unclear to what extent the information gathering leads to decisions related to complex situations, making this type of leadership a rather uneven fit for dealing with the $3^{\text {rd }}$ stage of internationalization, yet building alliances and having access to pre-emptive information about market costs and operational saturation levels may prove of assistance.

Ethical leadership is satisfied by maximizing economic outcomes that benefit owners while not engaging in anything prohibited by laws and moral standards [24], [28]. While it serves the interest of the organization in achieving economic success for the organization it does so by balancing values and norms considered important by all stakeholders involved. This style of leadership, while preferred and valued, can add value to an organization, yet it is unclear how it may find solutions to remedy lack of organizational resources for further expansion plans.

Spiritual leadership, seen by some theorists as a mere extension of the ethical style, received complete credit here and is seen as leadership oriented towards helping others to accomplish shared objectives by facilitating "individual development, empowerment, and collective work that is consistent with the health and long-term welfare of followers[27], [28]". A number of theorists have elongated the above to include the organization also as a benefactor of its intentions and orientation. It can be inferred that such leaders by having followers' needs as of primordial scope may be able to affect organizational performance due to employees' commitment to goals. One of these goals can be better decisions on internationalization related decisions, yet to what extent leaders can assess and act upon external information or manage complex information remains to be proven by further research and measurement.

Authentic leadership is based on positive core values such as honesty, self-sacrifice, kindness, fairness, accountability, and optimism as the style has often been associated with ethical leadership [28]. These core values motivate authentic leaders to do what is right and fair for followers and stakeholders, and to create a special type of relationship that includes high mutual trust, transparency, guidance toward worthy shared objectives, and emphasis on follower welfare and development. These leaders have a high self-awareness about their values, beliefs, emotions, self-identities, and abilities. The point worth making is the void in extant research regarding a linear relationship between core values and success in the international arena, when resources are exhausted or operational saturation reached.

\section{LEADERSHIP AND THE SIGMOID}

Intersecting a firm's goals, of higher degrees of internationalization, and its existing leadership style — as concepts but also as practices - is becoming an imperative for an SME/MNE's sustained performance as it pursues global markets. Clearly, internationalization, leadership, and firm performance are closely linked: based on firm's performance leaders decide if they need to reach new markets if they have the operational ability to do so and such decisions inherently lead to lower of higher degree of internationalization. An SME/MNE's leader must play an integral role in making the appropriate decisions about the appropriate degree of internationalization and the operational resources needed for such strategic effort. The choice of what market to enter, timing of entry and the scale - commitment of resources - all are leadership generated actions and can impact a company's ability to adapt to new demand of its operations, as well as support pre-expansion activities [29]

In looking at the sigmoid depiction above one sees that once a firm reaches the third stage, when results diminish or negative return are registered, a close dependency seems to emerge between decisions and results. Therefore, all signs seem to point to leadership as the active ingredient capable of preventing the diminishing results expected to occur during the third stage represented in the sigmoid, due to its access to privilege with regards to decision making. Closing the loop, we assert that leadership's derived decisions and global mindset influence the degree and stage of internationalization [12], [29]. The questions that need asking are: which leadership style and how leadership prevents the firm from reaching a growth stage where growth ceases to produce value for the organization.

Answering the first question, which style, can be arrived by developing a chart that summarizes the above findings with regards to leadership styles and their expected effect with regards to internationalization related decisions making process. The Table I below summarizes the traits defining each leadership style and its estimated effect upon the state of the internationalization sigmoid:

\begin{tabular}{|l|l|l|}
\hline \multicolumn{3}{|c|}{ TABLE I: LEADERSHIP STYLE IMPACT } \\
\hline Style & Traits & Impact \\
\hline Sustainable & $\begin{array}{l}\text { Integrity, ability to deal } \\
\text { and solve complex } \\
\text { issues }\end{array}$ & High \\
\hline Situational & $\begin{array}{l}\text { Adapts to followers } \\
\text { maturity level }\end{array}$ & Low \\
\hline Transformational & $\begin{array}{l}\text { Charismatic, visionary } \\
\text { and inspirational }\end{array}$ & Low \\
\hline Transactional & $\begin{array}{l}\text { Serves short-term } \\
\text { organizational needs }\end{array}$ & Low \\
\hline Distributed/shared & $\begin{array}{l}\text { Shared responsibilities } \\
\text { between leaders }\end{array}$ & Medium \\
\hline Relational & $\begin{array}{l}\text { Collective activities, } \\
\text { builds social networks } \\
\text { and alliances }\end{array}$ & Medium/High \\
\hline Ethical & $\begin{array}{l}\text { Values and norms based } \\
\text { economic actions }\end{array}$ & Medium/High \\
\hline Spiritual & $\begin{array}{l}\text { Builds high employee } \\
\text { commitment through } \\
\text { attention to their welfare }\end{array}$ & Medium \\
\hline Authentic & $\begin{array}{l}\text { Enforces positive core } \\
\text { values in operational } \\
\text { model }\end{array}$ & Medium \\
\hline
\end{tabular}

According to the Table I above we advance that a leadership style based on sustainability, relational and ethical traits is the best fit for an organization's 
expansionary goals. The rationales for it is that a firm needs a leader with an unusual set of abilities, that is capable of solving complex problems and is able to enact adaptive organizational changes; changes needed in order to affect the saturation in growth posted by the sigmoid theorists and model above. Adding the relational and ethical traits is due to the need to adopt a decision making structure that includes at times the context of building alliances and networks that are served and serviced based on ethical norms and values. The latter is quite interdependent as knowing that a firms leadership is ethical may allow it to participate in trustworthy alliances; alliances that may provide the financial and operational support to balance the lack of internal resources needed for reaching additional levels of internationalization.

A model set of activities, the answer to how, would be for leaders to conduct rigorous assessments with regard to the resources needed for pursuing additional globalization efforts. Once the results are known, additional resources should be allocated if necessary and if available. If the additional costs are not feasible, the process can be stopped, even if this means reaching a mediating operational plateau results wise. Fig. 2, displayed below, is depicting the role that leadership must play if the sigmoid third-stage consequences are to be ameliorated, changed, countered, or not allowed to materialize.

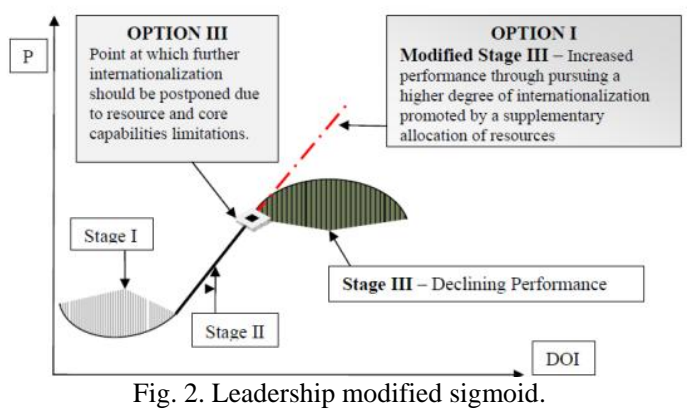

Therefore, an organization's leadership has two options that it can pursue: match a higher degree of internationalization with complimentary resources, resulting in a continuous second stage; or postpone any new global expansion in view of resource limitations, therefore eliminating consequences that could emerge by pursuing excessive internationalization. A point should be made with regards to committing additional resources if such allocation would carry a higher cost than the expected transaction benefits [8].

\section{CONCLUSIONS, LIMITATIONS, AND FURTHER RESEARCH}

The considerations above have not arrived at an absolute leadership style to be employed for best internationalization decisions during the time when operational abilities have been spent. Knowing that the third stage of internationalization occurs as a result of a MNE's inability to cope with increased demands upon its resources stemming from growing globalization demands, it appears only natural to look for answers to prevent it. Further research and dialogue are and will be needed so as to define the linear -if it is linear -correlation between leadership and the modality of accessing the pertinent quality information for the purpose of enabling a better decision making process with regards to increasing or reducing a MNE's degree of internationalization. Having the right information will be the key to possibly addressing the organizational deficiencies, yet what leadership style would be in control will largely impact how such information will be understood, disseminated and acted upon. What information or knowledge is thought to offer these pertinent solutions for a leadership to draw upon for strategic direction? So far leadership seems to only provide a nascent foundation for a control model, yet one could start with a benefit vs. cost analysis punctuated by field and organizational needs vs. MNE's core capabilities and available resource inventory.

This paper aims not only at critically reviewing contemporary research of the internationalization process but also at pointing out the active role to be played by a firm' leadership during this process and advance a leadership style that may be best fitted for addressing new developments in the life of a firm. Leadership is advanced as something quite different from management; that is, as both a reactive and proactive solution for dealing with the effects of a changing economic, business, and global environment. Harvesting successful results from an international expansion of operations is therefore a result of leadership activities. In brief, a multinational's leadership is the single most important factor capable of changing the 3-stage sigmoid. The intersection of leadership and internationalization suggests that organizations must make efforts to predict and prevent the effects of excessive internationalization upon an MNE's performance level. Solutions need to give careful consideration to available resources and how those resources should be allocated. Two actions may result from such consideration: postpone further globalization or pursue it by allocating the required supplementary resources.

Ideally, a firm's leadership is seen as charged with enabling the existence of an organization that has access to information based on either internal reports and market related data, which in turn would provide meaningful information for an educated decision making process with regards to strategy formulation and the undertaking of any additional globalization efforts. The latter would provide an operational guideline for either dealing with unexpected changes or forecasting the resources and information needed for further expansion activities. The styles of leadership see as most malleable to the considerations of preventing a $3^{\text {rd }}$ stage from being prematurely encountered or for posing the ability to prolong the growth stage is seen as a combination of sustainable, relational and ethical. These decisions are by no means exhaustive and leave room for debate.

One of the limitations of the model is that it does not take into consideration the effect of unpredictable external factors affecting international performance-factors outside a leader's realm of knowledge, such as economic downturn in a geographic or economic area with global impact, political and social unrest, natural disasters, and possibly terrorism. Further research is expected to clearly articulate a set of guidelines for assessing organizational possibilities vis-à-vis the requirements of maintaining a continuously positive performance through internationalization. Postponing and possibly preventing the last stage from 
occurring should be the centerpiece of further research.

Another limitation lies in the fact that the paper does not offer a comprehensive model for studying leadership styles and it arrives at conclusions mostly supported by theorists that believe that internationalization success is highly dependent on the degree of such expansion.

Higher degrees of internationalization are therefore supported and promoted as semi-guarantees of organizational performance. Theorists, such as Hennart have disagreed with such equivalence and such point would further affect the supported correlation and absolute link between leadership and its upon the internationalization sigmoid.

\section{REFERENCES}

[1] P. W. Beamish, A. J. Morrison, A. C. Inkpen, and P. M. Rosenzwig, "The internationalization process," International Management, McGraw-Hill, chapter 1, pp. 3-16, 2003.

[2] M. Glaum and M.-J. Oesterle, "40 years of research on internationalization and firm performance: more questions than answers?" Management International Review, vol. 47, no. 3, pp. 307 317, 2007.

[3] F. Contractor, "Is international business good for companies? The evolutionary or multi-stage theory on internationalization vs. the transaction cost perspective," Management International Review, pp. 453-475, 2007.

[4] A. Riahi-Belkaoui, "The effects of the degree of internationalization on firm performance," International Business Review, vol. 7, no. 3, pp. 315-321, 1998

[5] D. Sullivan, "Measuring the degree of internationalization of a firm," Journal of International Business Studies, vol. 25, no. 2, pp. 325-342, 1994.

[6] S. Tallman and J. Li, "Effects of international diversity and product diversity on the performance of multinational firms," Academy of Management Journal, vol. 39, no. 1, pp. 179-196, 1996.

[7] J.-F. Hennart, "The Theories of Multinational Enterprises," in R. A Brewer, The Oxford Handbook of International Business, Oxford University Press, pp. 127-149, 2001.

[8] J.-F. Hennart, "The theoretical rationale for a multinationality and performance relationship," Management International Review, vol. 47, no. 3, pp. 423-443, 2007.

[9] J. Johanson and J. E. Vahlne, "The Mechanism of Internationalization," International Marketing Review, vol. 7, no. 4, pp. 11-24, 1990.

[10] S. Hollensen, Global Marketing in the Firm, Global Marketing, $2^{\text {nd }}$ ed., Pearson Education, Essex, England, chapter 1, pp. 5-16, 2007.

[11] E. Garcia-Canal and C. Lopez-Duarte, "Stock Market Reaction to FDI Interaction between Entry Mode and FDI Attributes," Management International Review, vol. 47, no. 3, pp. 393-422, 2007.

[12] C. M. Chiarra, "Success factors in SME's internationalization process: An Italian investigation," Journal of Small Business Management, vol. 40, no. 2, pp. 144-153, 2002.

[13] C. Kalantaridis, "Internationalization, Strategic Behavior, and the Small Firm: A Comparative Investigation,” Journal of Small Business Management, vol. 42, no. 3, pp. 245-262, 2004.

[14] P. W. Beamish and J. Lu, "International diversification and firm performance: the s-curve hypothesis," Academy of Management Journal, vol. 47, no. 4, pp. 598-609, 2004.
[15] J. Johanson and J. E. Vahlne, "The internationalization process of the firm: a model of knowledge development and increasing foreign commitments," Journal of International Business Studies, vol. 8, no. 1, pp. 23-32, 1977

[16] L. Eden, and D. Thomas, "What is the shape of multi-nationalityperformance relationship?" Multinational Business Review, vol. 12 no. 1, 2004, pp. 89-110, 2004.

[17] M. Javidan and J. L. Walker, "A whole new global mindset," People and Stategy, vol. 35, no. 2, pp. 37-41, 2012

[18] J. Kouzes, and B. Posner, The Leadership Challenge. San Francisco, Calif: Jossey-Bass, pp. 5-9, 1987.

[19] F. F. Cotae, "Looking at the Link between Leadership, Organizational Learning and the Sigmoid," Global Management Journal, vol. 2, no. 1, pp. 3-16, 2010.

[20] A. Zaleznik, "The leadership gap," The Executive, vol. 4, pp. 7-22, 1990.

[21] M. Javidan, M. Teagarden, and D. Bowen, "Making it Overseas," Harvard Business Review, vol. 4, pp. 12-19, 2010.

[22] J. P. Kotter, "What leaders really do," Harvard Business Review, vol 68, pp. 103-111, 1990.

[23] M. L. Guarriello, "The management of leadership," Hospital Materiel Management Quarterly, vol. 17, no. 3, pp. 17-21, 1996.

[24] L. Metcalf and S. Bean, "Leadership for sustainability: an evolution of leadership ability," Journal of Business Ethics, vol. 1, no. 12, pp. 369-384, 2012

[25] T. Keller, "Parental images as a guide to leadership sense making: an attachment perspective on implicit leadership theories," The Leadership Quarterly, vol. 14, pp. 141-160, 2003

[26] B. Fenberg, C. Ostroff, and W. Burke, "The role within-group agreement in understanding transformational leadership," Journal of Occupational and Organizational Psychology, vol. 7, no. 8, pp. 471488, 2005.

[27] T. B. Searle and J. E. Barbuto. "Servant leadership, hope and organizational virtuousness: a framework for exploring positive micro and macro behaviors and performance impact," Journal of Leadership and Organizational Studies, vol. 18, pp. 107-117, 2011.

[28] G. Yukl, Leadership in Organization, $8^{\text {th }}$ ed, US Prentice Hall, 2013, ch. vol. 12, pp. 310-335.

[29] C. Hill and T. McKaig, Global Business Today, $3^{\text {rd }}$ Canadian ed., McGraw-Hill Ryerson, 2012

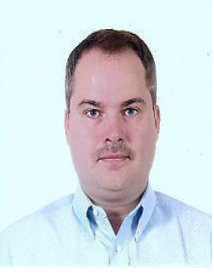

Frank F. Cotae has over 20 years of experience as manager, entrepreneur, consultant and instructor. He is currently a professor of international business at Bassett School of Business, Mount Royal University, Calgary, Canada. He has obtained a doctorate in international business management from ISM at St. John's University, New York City, NY, US, an MBA from University or Arizona at Phoenix, Phoenix, US and a BA in finance from California State University, Fullerton, US. Frank Cotae's research interests surround the internationalization, operations management, organizational learning, resource optimization and leadership studies. His research has been published in journals such as: Journal of American Academy of Business,

Cambridge; International Journal of Business Studies and Current Topics in Management.

Dr. Cotae is a member of the Academy of International Business, Academy of Management and FITT Canada, a reviewer for International Business Review journal, International Journal of Entrepreneurship and is a Contributing Editor for the Journal for Global Commerce Research . 